Article

\title{
Contributing Project Characteristics and Realized Benefits of Successful BIM Implementation: A Comparison of Complex and Simple Buildings
}

\author{
Svetlana Olbina * and Jonathan W. Elliott \\ Department of Construction Management, Colorado State University, 224A Guggenheim Hall, Fort Collins, \\ CO 80523, USA \\ * Correspondence: Svetlana.Olbina@colostate.edu; Tel.: +1-970-491-7026
}

Received: 21 June 2019; Accepted: 24 July 2019; Published: 26 July 2019

check for updates

\begin{abstract}
Researchers have explored Building Information Modeling (BIM) utilization on complex buildings. However, limited research has been conducted investigating BIM implementation on simple projects. This study explored the perceptions of Architects, General Contractors and Owners regarding the project characteristics that impact successful BIM implementation, and the realized benefits thereof, on complex commercial buildings versus parking garages. A survey comprised of the project characteristics and realized benefits of BIM implementation identified by Dodge Data \& Analytics was distributed. Exploratory Factor Analysis was conducted to identify the empirical groupings of successful BIM implementation characteristics and realized benefits thereof. Factor means were calculated and compared using ANOVA and t-tests. Statistical comparisons revealed no significant differences by building type. For project stakeholders, a significant difference was only observed on owner's mean perceptions of technology-related characteristics when compared to architects. Previous research indicates that Architecture, Engineering, and Construction (AEC) stakeholders believe BIM is beneficial for large and complex projects. With the exception of technology-related project characteristics, findings reveal no statistical differences for project characteristics impacting successful BIM utilization or the realized benefits of BIM implementation given building type. This finding provides empirical evidence that various stakeholder groups view BIM as a universal AEC process that provides benefits on both complex and simple projects.
\end{abstract}

Keywords: exploratory factor analysis; BIM Implementation; BIM benefits; project stakeholders

\section{Introduction}

According to the National Institute of Building Sciences (NIBS) [1] Building Information Modeling (BIM) is a business process that generates data to be used during the various phases of a building's life cycle including design, construction, operation and maintenance. Whereas the product of the BIM process, e.g., a singular Building Information Model, comprises a digital representation of a facility that can be used as a shared knowledge resource by different stakeholders involved in a building project. BIM adoption within the Architecture, Engineering, Construction, Operation and Maintenance (AECOM) industries has been steadily increasing. A survey of Architecture, Engineering and Construction (AEC) stakeholders in the United States indicated that in 2008, about one-third (28\%) of the AEC industry utilized BIM, while in 2012 more than two-thirds (71\%) used BIM; a notable 75\% increase in the BIM adoption rate in the five-year period [2]. According to Antwi-Afari et al. [3] and NIBS [1], the increase of BIM utilization is due, in part, to the realization of the numerous benefits that BIM provides to building project stakeholders.

In addition, research indicates that there are multiple factors that facilitate the successful implementation of BIM on a project. Human, technical, technological, and financial resources 
are the main drivers of successful BIM implementation while project, policy and industry-related factors have a moderate influence. The most significant factors that influence BIM implementation are availability of qualified staff, effective leadership and availability of information technology [4].

Studies investigating the project characteristics that impact the successful implementation of BIM and the realized benefits of BIM implementation have been conducted on large, often complex, commercial projects [4-18]. However, less attention has been given to classifying the project characteristics that impact success of BIM implementation and BIM benefits realized on simpler projects [19]. Dodge Data \& Analytics [5] classifies hospitals, laboratories, data centers, entertainment buildings, industrial/manufacturing facilities and transportation buildings (e.g., airports, major railway stations) as complex projects. Execution of complex projects is more challenging, risks may be greater and need for improvement more important [20]. On the other hand, parking garages, as an example of simple structures, do not necessarily require complex mechanical, electrical and plumbing systems and building envelope. For these reasons, they use simpler execution methods and typically impose less risk. Large projects also have more capacity to invest in BIM and ability to establish a managerial structure to support BIM processes whereas small projects do not always have these resources [20,21]. Some project participants find that implementing full BIM processes might be too complicated and not feasible on small projects. They also feel that building information models provide too much detail which might not be necessary on small projects [20]. According to the National Building Specification (NBS) National BIM Report [21] only about half of the small practices are using BIM. The same report indicates that BIM has been used more on large public projects than on the smaller projects. Therefore, according to the previous studies, BIM implementation is viewed as impactful on large projects but less impactful on smaller projects.

The goal of this research was to explore the perceptions of different project stakeholders (Architects, General Contractors and Owners) regarding BIM implementation on two specific project types (commercial buildings as complex buildings and parking garages as simple buildings). In this research, commercial buildings included: institutional, core and shell, multi-family residential, office, and health care buildings. The overarching purpose of the research was to explore the empirical groupings (e.g., factor structure) of 1) the reported factors that impact successful BIM implementation; hereafter "implementation characteristics" (IC) and 2) the reported realized benefits of BIM use; hereafter "implementation benefits" (IB) for Architects, General Contractors and Owners. The means statistics were calculated for the BIM-IC and BIM-IB factor groupings and compared by stakeholder category as well as between commercial building and parking garage projects.

\section{Literature Review}

\subsection{Benefits of BIM Implementation on the Project}

Studies of complex projects indicate that BIM use increases productivity in the construction industry and improves design, construction and maintenance practices $[3,6,8,22,23]$. According to McGraw Hill Construction [2], AEC respondents reported reduced project cost, reduced schedule duration, and increased project profit, as the long-term benefits of BIM use. In a later survey, the majority of AEC professionals (85\% and $88 \%$, respectively) identified reduced final cost and completion time as the benefits of BIM utilization on complex projects [5]. Various studies indicated that the use of BIM improved effectiveness, efficiency, and quality at the construction task-level as well as contributed to higher quality overall project deliverables $[9,10,23,24]$. Literature also revealed that the BIM process improved the quality of information needed for decision-making and risk management practices $[3,6,8,9,25,26]$. Companies that utilize BIM benefit from gaining a competitive advantage, increasing market access and maintaining repeat business [2,8]. According to McGraw Hill Construction [2], use of BIM leads to reduced errors in construction documents, fewer change orders and reduced rework as well as decreased number of claims and litigation. Almost $74 \%$ of the AEC professionals reported a $5 \%$ decrease in the number of requests for information (RFIs) on 
projects implementing BIM [5]. Research by Antwi-Afari et al. [3] and Cavka et al. [16] indicated that improved coordination and construction planning, and enhanced exchange of information and knowledge management were some of the major benefits of BIM. Use of BIM also helps with the delivery of sustainable buildings and achieving more energy-efficient design $[9,10,27]$.

Research specific to less complex building projects was limited. Won and Lee [19] conducted a case study of pre-cast parking garage structures on which BIM was used for design authoring and review, 3D design coordination, phase planning, quantity take-off, and construction system design. BIM use on this project resulted in improved communication, work efficiency, technological capability, and in equipping personnel with advanced BIM skills. However, no independent studies were found that empirically compared BIM utilization between complex and simple projects.

\subsection{Stakeholder Perceptions of the Benefits of BIM}

The utilization of BIM brings various benefits to different project stakeholders such as designers, contractors, subcontractors and owners. BIM enhances collaboration among the project team members throughout the project lifecycle which leads to delivery of better project outcomes [23,28]. BIM also improves communication among the stakeholders; for example, communication between clients and designers is enhanced due to the use of building information models for design visualization [29]. Benefits of using BIM are shared among the project participants; for example, benefits experienced by the design team could include less rework and fewer RFIs which provide benefits for the contractors in the construction phase as well as overall benefits to the client. As BIM benefits can be shared among clients, designers, and contractors, stakeholders are not exposed to loss during this collaboration, and, therefore, they are more motivated to implement BIM on projects [30]. Another example of BIM benefits experienced by multiple stakeholders is a location-based design process that helps design team minimize waste of time spent on building information modeling [31]. This process uses the concept of BIM level of development (LOD) based on the construction activity sequence, location and schedule as well as the needs of the end-users of the model in the specific construction phases.

Architect-Specific BIM Benefits. BIM allows designers to work more efficiently and flexibly [32]. The use of BIM facilitates a collaborative design; thus, architects are able to market new business and offer new, better-quality services to clients $[2,12,32]$. In the project design phase, BIM use helps with early detection and correction of errors and, therefore, results in fewer design errors, more accurate design, enhanced coordination and productivity $[2,9,10,13,33-35]$. BIM use enables architects to compare design alternatives resulting in more efficient, cost-effective and sustainable design solutions [28]. BIM also helps architects to quickly perform building performance analysis of different scenarios throughout the building life cycle [9].

The use of various BIM tools enhances architectural creativity as architects are able to explore and model complex building design concepts and spend more time on designing rather than drafting [24]. Architects are also able to produce better quality BIM-based designs as compared to designs presented by $2 \mathrm{D}$ drawings and then use these building information models for automated generation of accurate 2D drawings [6,12,35]. It is important that designers have their share of the economic benefits due to use of BIM; otherwise, they will have no incentives to adopt BIM in their practices [24].

General Contractors-Specific BIM Benefits. In a project preconstruction phase, BIM provides faster cost estimating, more precise scheduling of construction activities and improves the processing of construction documents [10,34]. BIM is beneficial for providing detailed cost estimates using the material data obtained from multidimensional CAD designs including labor rates, bill of materials, and construction and installation schedules [7]. Contractors can obtain accurate quantities of building materials and components from building information models and then, using these quantities, order building materials and components electronically, resulting in just-in-time delivery to the jobsite and increased workers' productivity [28]. Use of BIM can also be beneficial for determining the optimal crane locations on a construction site as well as the optimal locations of material storage. This approach optimizes material transport too resulting in cost and time savings [17]. 
During the construction phase of a project, BIM use leads to faster project completion times and lower construction costs $[7,9,10]$. As mentioned earlier, fewer design errors and fewer RFIs lead to reduced rework, reduced schedule delays, and, ultimately, increased Return on Investment (ROI) $[2,9,19,33]$. As shown by Won and Lee [19], construction companies experienced BIM-related ROI of 300-500\%. BIM also provides an opportunity for contractors to optimize collaboration among the project stakeholders by improving the design, construction, and maintenance processes $[9,11]$. Since this multidisciplinary collaboration and integration leads to fewer design errors, RFIs, change orders and less rework, it provides cost benefits not only to contractors but designers and clients as well $[7,28]$.

Utilization of BIM improves constructability of the final design leading to better project quality [5,22]. BIM use for visualizing the construction sequence is particularly beneficial on complex projects [12]. Use of 4D BIM can help schedulers visualize the construction sequence and allocate resources of each construction activity [18]. The 4D method developed by Shan and Goodrum [18] helps select the most optimal project start date in regard to weather (i.e., temperature and humidity) as well as the best location for a project in terms of the lowest construction cost. The use of 4D BIM also helps construction professionals perform schedule analysis and visualize productivity changes for different project execution scenarios. Ratajczak et al. [36] developed a mobile field application that integrated a BIM-based model with Augmented Reality. This application provides daily progress and performance data of construction work and helps site managers obtain a better understanding of the project and make fast decisions and corrective actions. With the use of the application, site managers can automate their work and improve construction performance as the application monitors and controls construction activities at different locations while the site manager is conducting field inspection. Use of this application resulted in $50 \%$ time savings.

Contractors can also benefit from accessing building information models and solving construction problems on site as soon as they arise [6]. In addition, BIM use for off-site prefabrication of building components reduces the cost and duration of a project $[5,6,12,14]$. BIM utilization for prefabrication and visualization also decreases the number of construction workers on site which can result in better safety performance [7].

Owner-Specific BIM Benefits. Owners are willing to adopt BIM if they see its effectiveness [7]. Benefits due to use of BIM realized by both contractors and designers increase owner's revenue by saving time and cost $[7,30]$. The majority of the owners noted that BIM use improved their ability to plan project phasing and logistics and provided better construction documents. Owners reported that BIM utilization improved labor productivity and decreased the need for site labor due to prefabrication on complex projects [5]. Owners also indicated that reduced document errors and omissions were the top benefits of BIM use while, similar to contractors, owners noted that BIM use was beneficial due to reduced rework [2].

As-built building information models can be very beneficial to the owner for facility management and building operations [30]. If as-built models are properly created during the construction phase, they can be used by the owner to manage and operate the building more effectively and efficiently [24]. In other words, after a project is handed over to the owner; i.e., in the operation and maintenance phase of the project, building information models can be used to simulate and improve maintenance processes and reduce facility management costs [37].

BIM-based tools help owners improve facility management; more specifically BIM use results in decreased time periods when equipment is not available, decreased cost, increased customer satisfaction, and enchased information exchange between different stakeholders. BIM also helps the owner optimize and improve maintenance activities such as timely ordinary maintenance, faster and more effective extraordinary maintenance, storing maintenance data, continuously updating maintenance schedules, implementing predictive maintenance, and performing mandatory safety checks [38]. BIM-based 3D visualizations of the building systems could help a building operator identify the source of a problem [16]. 
BIM can also be used to analyze energy performance during building operation as well as to compare various energy performance alternatives. This approach can contribute to reductions in both building environmental impacts and operating costs [28]. Verghote et al. [39] investigated benefits of using BIM for wayfinding during emergency response in the building occupation phase. They found that the use of 3D models for visualization significantly improved the wayfinding performance of participants with low spatial cognition.

\subsection{Project Success: BIM Implementation Characteristics}

Previous research has identified various factors (e.g., Implementation Characteristics) that affect the success of BIM implementation on construction projects. Ozorhon and Karahan [4] grouped the critical success factors of BIM implementation into five distinct categories; human, industry, project, policy, and resource-related. Within the human-related category, training of employees was considered critical for successful implementation of BIM [4,28]. Research by Ratajczak et al. [36] and Koseoglu et al. [23] revealed that adoption of information and communication technology in the construction industry has been slow due to lack of BIM-knowledgeable employees as well as different BIM learning curves of project stakeholders. According to Dodge Data \& Analytics [5], the majority of responding owners, designers, and contractors stated that lack of BIM skills and insufficient BIM training for inexperienced team members were the most significant technology-related obstacles to project success. Won and Lee [19] identified that adequate BIM training programs, and proactive participation of practitioners led to successful BIM implementation. From the human-behavior perspective, Lee et al. [25] posit that personal competency comprising self-efficacy, personal innovativeness, and external and internal pressure influence the acceptance of BIM. According to Dodge Data \& Analytics [5], designers, contractors and owners reported that the highest rated obstacles to BIM implementation were a lack of AEC members' involvement during all project phases and the existence of AEC team members who are not supportive of using advanced BIM tools.

Ahn et al. [6] advised establishing a specific organizational structure that would support BIM adoption. More specifically, they recommended creating a BIM/VDC department that would be responsible for providing BIM education. Developing and implementing BIM education programs in a company in the form of BIM courses, BIM training sessions, and BIM forums are crucial for the successful adoption of BIM [6]. A study by Son et al. [40] focused on architectural firms and identified computer self-efficacy and user's perceptions of BIM usefulness as the external variables that might influence their adoption of BIM. In addition to BIM training, BIM experience level within the firm, effective leadership and top management support are also considered human-related factors that play an important role in BIM adoption [4,7,40]. In the nationwide survey by Dodge Data \& Analytics [5] enhanced communication among team members was rated as an important BIM success factor by $53 \%$ of project owners, $47 \%$ of contractors and $62 \%$ of architects who responded to the survey. According to the same survey, project success would be hindered if an owner organization does not sufficiently understand the value of using advanced tools such as BIM [5].

Various factors in project-related category might influence BIM implementation on the project. Coordination among project parties and establishing collaborative work environment affect the success of BIM implementation [3,4,15,41]. According to Dodge Data \& Analytics [5] the majority of the designers $(60 \%)$, contractors $(68 \%)$ and owners $(73 \%)$ surveyed indicated that improved team work and collaboration were the BIM-oriented processes that contributed most to the success of complex projects. The second highest proportion of owners (68\%) and more than half of designers (56\%) and contractors $(52 \%)$ considered BIM-integrated project meetings to be a critical success factor. In addition, the client's request for BIM use on the project and the willingness of project managers, field engineers and architects to adopt BIM are considered critical success factors for BIM implementation in projects $[4,15]$. In other words, integrated project delivery mindset is one of the crucial drivers of BIM success [23].

Dodge Data \& Analytics [5] observed that the majority of all the respondents (i.e., 73\% of owners, $58 \%$ of designers and $59 \%$ of contractors) thought that owner selection of design/construction firms 
that are experienced in using BIM is a critical success factor for BIM implementation. As expected, contractors $(72 \%)$, more than any other stakeholder, valued early trade contractor involvement, while owners (63\%) valued more project design development in BIM as compared to architects (50\%) and contractors $(35 \%)$. In addition, more general contractors $(68 \%)$ than designers $(36 \%)$ and owners $(53 \%)$ thought the early general contractor's (GC's) involvement with design models was a critical success factor [5]. Won and Lee [19] posit that efficient design change processes led to successful implementation of BIM on a project. Liu et al. [24] explored BIM use in the Chinese AEC industry and identified the following eight success factors for BIM collaboration; IT capacity, technology management, attitude and behavior, role-taking, trust, communication, leadership, learning and experience. According to Koseoglu et al. [23], if stakeholders are experiencing fast and successful project outcomes due to use of BIM that would lead to successful BIM implementation. In addition, ability to maintain continuous monitoring and controlling during the project execution contributes to BIM success [23].

Project size, project type, and complexity of project are additional project-related factors that might influence the decision to use BIM on a project $[3,4,7,10,15,23,41]$. However, Ozorhon and Karahan's [4] study focusing on Turkish construction sector indicated that project size has a moderate influence on successful BIM implementation. A study by Cao et al. [10] of the Chinese construction industry shows that owners are more inclined to use BIM on larger, non-residential and public projects. Won et al. [15] pointed out that the complexity of a project influences the success of the BIM implementation. According to Ozorhon and Karahan [4], in Turkey, BIM adoption is more likely to occur on simple residential projects rather than on complex industrial projects.

With regard to the policy-related factors impacting project success, consulting, supportive organizational culture and the BIM implementation policies of the company are considered some of the most influential factors on BIM adoption $[4,15,23]$. BIM implementation requires organizational reform which is one of the main obstacles to BIM success $[15,16]$. In reference to organization's culture, the following external variables affect acceptance of BIM: consensus on appropriation and the organization's competency consisting of collective efficacy, organizational innovativeness, and top management support $[25,33]$. In regard to company size, in the Turkish construction industry, small companies have a more supportive organization culture for BIM implementation than large companies that are reluctant to innovations [4]. Organizational factors such as company culture that is resistant to change prevent BIM implementation [36]. On the other hand, an organizational culture that supports BIM training as well as willingness to share information among project stakeholders can contribute to successful BIM implementation [15,16,23,42]. From this perspective, almost half of owners, designers and contractors reported that owner openness to innovative team structures, agreements and work processes contributes to project success [5]. For process collaboration, a standardized BIM process, development of guidelines for BIM implementation, and the involvement of all stakeholders in the BIM process are critical success factors [42]. Contractors perceived a company's BIM policy as a more influential critical success factor than did consultants [4]. Almost half of the owners $(45 \%)$, whereas fewer designers (19\%) and contractors (26\%), indicated a strong perceived value of having BIM guidelines and standards [5].

The availability of information, technology, qualified staff, and financial capital are reported as the top resource-related factors that impact BIM adoption [4,28]. Won at al. [15] posit that the level of BIM implementation depends on how well current BIM technologies are supported. BIM acceptance is dependent on the software compatibility and quality of the product outputs as well as the internal perceived usefulness and perceived ease of utilization [25,33,40]. According to Won et al. [15] the need for continuous investment is one of the main obstacles to BIM implementation. Furthermore, technical collaboration, poor interoperability and data compatibility were recognized as the barriers to successful BIM implementation while user-friendly interface and data security contributed to successful BIM implementation [9,42]. Ahn et al. [6] also advocated conducting research on utilizing BIM applications that provide the most value to the project and organization. In terms of availability of qualified staff, 
having an organizational structure of project teams and a BIM-manager on a project positively affect BIM implementation $[15,42]$. For the companies that utilize BIM, as well as their clients who benefit from BIM utilization, it is important to show that BIM implementation on a project provides a ROI [15].

\section{Research Questions}

Exploration of the literature revealed that a large proportion of the current BIM research has focused on complex commercial projects. However, limited research was found exploring the project characteristics that impact successful BIM implementation (BIM-IC) and the realized benefits of BIM implementation (BIM-IB) on simple projects. The current study was conducted in two phases. The first phase comprised the exploration of the factor structure of BIM-IC and BIM-IB based on items identified by Dodge Data \& Analytics [5]. Given the results of the Exploratory Factor Analysis (EFA), the research questions (RQ 1-4, phase two) below explored the perceptions of project characteristics (BIM-IC) that contribute to successful BIM implementation and the realized benefits thereof (BIM-IB) given building type (parking garages and commercial buildings) and project stakeholder (Architects, General Contractors and Owners).

RQ 1: Are differences in the perceptions of project characteristics that impact BIM implementation (BIM-IC) observed when compared by building type?

RQ 2: Are differences in the perceptions of the realized benefits of BIM implementation (BIM-IB) observed when compared by building type?

RQ 3: Are differences in the perceptions of project characteristics that impact BIM implementation (BIM-IC) observed when compared by project stakeholder?

RQ 4: Are differences in the perceptions of the realized benefits of BIM implementation (BIM-IB) observed when compared by project stakeholder?

\section{Methodology}

The Dodge Data \& Analytics [5] report on BIM utilization in complex buildings was used to identify the realized benefits of BIM implementation (BIM-IB) as well as the project characteristics which contribute to successful BIM implementation (BIM-IC). It should be noted that the stakeholders queried in the current study match those in the 2015 Dodge Data \& Analytics survey. It was also noted that the results of the Dodge Data \& Analytics [5] report were aggregated for a variety of complex buildings (hospitals, laboratories, data centers, entertainment buildings, industrial/manufacturing facilities and transportation buildings) without sub-aggregation given one particular building type. This method of comparison was chosen so that identical independent variables (i.e., Characteristics for successful BIM implementation identified by Dodge Data \& Analytics [5]) could be compared given the dependent variable (stakeholder and building type). As noted previously, the first phase of the research comprised the exploration of the factor structure of BIM-IC and BIM-IB via EFA. Given the factor loadings evident in phase 1, research questions 1 and 2 investigated the perception of various stakeholders using Analysis of Variance (ANOVA) for multi-level variable comparisons and post-hoc analyses (in the case of significant ANOVA findings). And finally, for research questions 3 and 4, the researchers utilized the student t-test to explore differences between the factors of BIM-IC and BIM-IB between commercial buildings and parking garages.

\section{Exploratory Factor Analysis}

As noted previously, realized benefits of BIM implementation (BIM-IB) and the project characteristics which contribute to successful BIM implementation (BIM-IC) were obtained from the survey created by Dodge Data \&Analytics [5]. According to Pett et al. [43] (p. 167) "The decision as to the number of factors to be retained should be based on an artful combination of the outcomes obtained from statistical indicators, the factors' theoretical coherence, a desire for simplicity, and the original goals of the factor analysis project." Therefore BIM-IB and BIM-IC were treated as distinct and 
separate scales and the emergent factor structure was evaluated independently for the BIM-IB and BIM-IC items created by Dodge Data \& Analytics [5]. According to Pett et al. [43] an unrotated factor solution rarely provides meaningful and understandable item clusters, and often indicates a general factor which may be a statistical artifact. Therefore, Principal Component Analysis was employed and a Varimax rotated factor solution was used to identify the emergent factor structure. Eigenvalues $>0.40$ on multiple factors were the initial criterion for survey item removal as suggested by Pett et al. [43]. Items with a factor loading $>0.40$ on a single component were grouped for analysis.

\section{Instrumentation}

A survey was developed based on the 2015 Dodge Data \& Analytics report on BIM utilization in complex buildings. A convenience sample of construction stakeholders was comprised of the contact list from the facilities management department of a public land grant university and an Engineering News-Record (ENR) Top 100 general contractor. The survey was distributed via email by the facilities department and general contractor to their list of contacts.

The survey instrument consisted of two main sections. The first section included demographic items and general questions which assessed respondent agreement with statements about the effectiveness of BIM. Survey section one and two were separated by a qualifying item which required respondents to identify that they reported BIM-IB and BIM-IC for a parking garage project or commercial building project. Skip logic was built into the survey and participants were directed to a parking garage-specific or commercial building-specific section two of the survey. The survey contained an identical list of BIM-IB and BIM-IC items obtained from Dodge Data \& Analytics [5]. Survey items only differed in that the words "parking garage" or "commercial building" was used given previous survey responses; e.g., "Based on your experience with BIM integration on a parking garage project (or commercial building for those respondents), please identify the level of impact, and whether it was negative on the successful implementation of BIM on the parking garage (or commercial building for those respondents) project".

For BIM-IB, respondents were asked to provide their level of agreement with the statement "The following benefit was realized when implementing Building Information Modeling (BIM) on the parking garage project (or commercial building for those respondents). Levels of agreement were reported on a 10-point scale $(1=$ Strongly Disagree to $10=$ Strongly Agree). A 10-point scale was chosen to increase the sensitivity and reliability of the scale [44]. The multi-item Likert scale was utilized to capture the respondents' beliefs at a finer level of granularity by (1) not sufficiently covering extremes of response and (2) forcing responses into a limited number of coarsely granulated categories [45]. Since respondents were 1) reporting their level of agreement with general benefits that could be realized on any project (regardless of project type or complexity) and 2) because the respondents, AEC professionals, were assumed not to be ignorant about the subject $[46,47]$ the authors choose a Likert scale without a neutral option.

The Dodge Data \& Analytics [5] survey identified 19 BIM-IB items as follows; increased understanding of proposed design solutions, increased ability to actively participate in the design process, increased ability to manage project scope, improved quality/function of the final design, ability to generate better construction documents, improved constructability of the final design, improved process and accuracy of estimating construction costs, improved accuracy and completeness of bids, improved ability to plan construction phasing and logistics, reduced number of RFIs, improved process of controlling construction costs, reduced final construction cost of projects, improved achievement of planned schedule milestone dates, increased predictability/fewer unplanned changes, reduced rework, improved labor productivity, reduced site labor due to increased offsite fabrication, reduced reportable safety incidents, and reduced material waste.

For BIM-IC, study participants were asked to rate the level of impact that a specific project characteristic (BIM-IC) had on the successful implementation of BIM. Specifically, respondents were asked to provide their perception of the impact of a project characteristic and whether the impact was 
positive or negative $(-5=$ Strongly Negative Impact; $0=$ No Impact; $5=$ Strongly Positive Impact). Unlike the BIM-IB items described above, the project characteristics presented in the survey might not be applicable to all project types. Therefore, the authors chose to include a "no-impact" (e.g., neutral) response option to avoid forcing participants to provide a level of positive or negative impact when they perceive a project characteristic to be unrelated to their AEC project experience [47].

The project characteristics included in the survey comprised the 13 BIM-IC items identified by Dodge Data \& Analytics [5]; BIM-integrated project meetings, early trade contractor involvement, project design development in BIM, GC's early involvement with design team models, selection of design/construction firms experienced in using advanced tool/methods, clients openness to innovative team structures, agreements and work processes, BIM/modeling guidelines from client, standards to guide implementation, clear definition of technology-related deliverables, availability of trained professionals using BIM tools, reduced software issues, improved team work and collaboration, and enhanced communication among team members.

\section{Results}

\subsection{Sample and Data Screening}

In total, 202 survey responses were received. Listwise deletion was employed to cull 41 incomplete surveys, yielding 161 responses. Participant responses were further screened using the demographic items "Have you worked on a construction project that has implemented or utilized Building Information Modeling?"; 24 respondents who answered "no" to this item were removed from the dataset. Since the target cohort for this study was general contractors, architects and owners, and given the small number of responses received from engineers (5), consultants (7) and other (1) stakeholders; these surveys were culled from the sample. In total, 82 responses were removed yielding an analysis sample of 120 participants. The demographic data of the cleaned sample is provided in Table 1.

Table 1. Demographic Characteristics $(n=120)$.

\begin{tabular}{lcc}
\hline \multicolumn{1}{c}{ Characteristic } & $\boldsymbol{n}$ & \% \\
\hline Gender & 23 & 19.2 \\
Female & 93 & 77.5 \\
Male & 4 & 3.3 \\
Prefer not to respond & & \\
Stakeholder & 46 & 38.3 \\
Architect & 59 & 49.2 \\
General Contractor & 15 & 12.5 \\
Owner & & \\
Building Type & 31 & 25.8 \\
Parking Garage & 89 & 74.2 \\
Commercial Building & & \\
\hline
\end{tabular}

\subsection{Sampling Adequacy for EFA and Internal Consistency Reliability}

The Kaiser-Meyer-Olkin (KMO) test was performed to ensure adequate sample size ( $\mathrm{n}=120)$ for EFA. The KMO test yielded a score 0.88 for BIM-IB and 0.84 for BIM-IC. According to Field [48], a KMO statistic between 0.80 and 0.90 is considered "great" evidence for sample adequacy when performing EFA. Internal consistency reliability statistics $(\alpha)$ of 0.95 and 0.88 were observed for BIM-IB and BIM-IC, respectively.

\subsection{Phase 1 Exploratory Factor Analysis}

Exploratory factor analysis was employed to investigate the empirical loadings of the items in the survey assessing the project characteristics that impact successful BIM implementation. Two BIM-IC factors emerged in the rotated factor solution using total eigenvalue $>1.00$ as a threshold for initial 
factor identification [43]. Two BIM-IC items ("selection of design/construction firms experienced in using advanced tool/methods", "clients openness to innovative team structures, agreements and work processes") loaded on single factors with similar eigenvalues (e.g., loadings within 0.12 points of one another) above the $>0.40$ benchmark. These items were removed. Investigation of the BIM-IC factor structure indicated six project characteristics loaded on a "human-related" factor and five project characteristics loaded on a "technology-related" factor. Eigen value loadings and the emergent two-factor structure of BIM-IC is provided in Table 2.

Table 2. Exploratory Factor Analysis: Building Information Modeling (BIM) Implementation Characteristics.

\begin{tabular}{ccc}
\hline BIM-IC Item & \multicolumn{2}{c}{$\begin{array}{c}\text { Eigen Values * } \\
\text { Technology Factor }\end{array}$} \\
\hline Improved Team Work and Collaboration & Human Factor & \\
BIM-Integrated Project Meetings & 0.837 & \\
Early Trade Contractor Involvement & 0.799 & \\
Project Design Development in BIM & 0.674 & \\
Enhanced Communication Among Team Members & 0.644 & \\
General Contractor (GC) Early Involvement in Design Team Model & 0.730 & \\
\hline BIM/Modeling Guidelines from Client & & 0.727 \\
Standards to Guide Implementation & & 0.691 \\
Clear Definition of Technology-Related Deliverables & 0.685 \\
Availability of Trained Professionals Using BIM Tools & 0.582 \\
Reduced Software Issues & 0.627
\end{tabular}

* Eigen Values below the 0.40 benchmark are not shown for clarity.

\subsection{Phase 2 Addressing Research Questions 1-4}

Next, the researchers explored the empirical loadings of the items in the survey assessing the realized benefits of BIM implementation. Four BIM-IB factors initially emerged in the rotated factor solution using total eigenvalue $>1.00$ as a threshold for initial factor identification [43]. Six BIM-IB items ("increased ability to manage project scope", "improved constructability of final design", "reduced number of RFIs", "improved process of controlling construction costs", "reduced final construction cost of projects", and "reduced site labor due to increased offsite fabrications") loaded on multiple factors with similar eigenvalues (e.g., loadings within 0.12 of one another) above the $>0.40$ benchmark. These items were removed. Three items ("generate better construction documents", "improved achievement of planned schedule milestone dates", and "improved labor productivity") loaded on two factors with Eigen values above the 0.40 benchmark, however, the Eigen values were markedly different by $0.23,0.33$ and 0.25 points, respectively. These items were evaluated and retained in light of the difference in factor loadings and based on their coherence to the content of the other items loading on the same factor [43].

Eigen value loadings for each item in the initial four-factor structure of BIM-IB is provided in Table 3. It should be noted that the fourth factor contained two items ("Reduced reportable safety incidents" and "reduced material waste") that loaded on a miscellaneous factor. While these items meet the quantitative benchmarks for EFA (e.g., total factor Eigen values $>1.0$ and item loadings $>0.40$ on a single factor) this factor was removed from the model given the assertion by Pett et al. [43] (p. 167) that "the decision as to the number of factors to be retained should be based on an artful combination of the outcomes obtained from statistical indicators, the factors' theoretical coherence, a desire for simplicity, and the original goals of the factor analysis project. Therefore, the "misc. factor" was removed and a three-factor structure was retained and factor means and statistical comparisons were completed only for the three (construction operations-, productivity- and design-related) factors which contained logical and coherent items. 
Table 3. Exploratory Factor Analysis: BIM Implementation Benefits.

\begin{tabular}{|c|c|c|c|c|}
\hline \multirow{2}{*}{ BIM -IB Item } & \multicolumn{4}{|c|}{ Eigen Values * } \\
\hline & $\begin{array}{c}\text { Construction } \\
\text { Operations Factor }\end{array}$ & $\begin{array}{l}\text { Productivity } \\
\text { Factor }\end{array}$ & $\begin{array}{l}\text { Design } \\
\text { Factor }\end{array}$ & $\begin{array}{l}\text { Misc. } \\
\text { Factor }\end{array}$ \\
\hline Generate better construction documents ** & 0.652 & & & 0.429 \\
\hline Improved process and accuracy of estimating construction costs & 0.851 & & & \\
\hline Improved accuracy and completeness of bids & 0.824 & & & \\
\hline Improved ability to plan construction phasing and logistics & 0.535 & & & \\
\hline Improved achievement of planned schedule milestone dates ** & & 0.746 & 0.416 & \\
\hline Increased predictability/fewer unplanned changes & & 0.847 & & \\
\hline Reduced rework & & 0.837 & & \\
\hline Improved labor productivity ${ }^{* *}$ & & 0.666 & 0.420 & \\
\hline Increased understanding of proposed design solutions & & & 0.882 & \\
\hline Increased ability to actively participate in design process & & & 0.770 & \\
\hline Improved quality/function of final design & & & 0.602 & \\
\hline Reduced reportable safety incidents ${ }^{* * *}$ & & & & 0.822 \\
\hline Reduced material waste *** & & & & 0.784 \\
\hline
\end{tabular}

${ }^{*}$ Eigen Values below the 0.40 benchmark are not shown for clarity. ${ }^{* *}$ Dual Loading Item with Eigen Values above the 0.40 benchmark were retained in the factor with high loading. ${ }^{* * *}$ These items were deemed unrelated and the factor "misc. factor" was not used for mean comparison.

Given the observed two-factor structure of BIM-IC, research question 1 investigated the perceptions of BIM Implementation Characteristics for all stakeholders by building type (e.g., parking garages versus commercial buildings). Results revealed no significant difference (Table 4) in the BIM-IC factor means based on building type. It should be noted that the mean scores $(\mathrm{M}=6.84-8.78)$ for the human- and technology-related factors indicate a "medium" to "strong" positive impact of the human and technology-related factors on the successful implementation of BIM on both parking garages and commercial buildings. While these statistics indicate that project stakeholders perceive no difference in the impact of human- and technology-related project characteristics on the success of BIM implementation, the impact of these factors was positive regardless of whether the building being constructed was a commercial building or a parking garage.

Table 4. BIM-IC: Human and Technology Factor by Building Type (RQ1).

\begin{tabular}{ccccccc}
\hline Variable & $\mathbf{N}$ & $\mathbf{M}$ & $\mathbf{S D}$ & $\mathbf{t}$ & $\mathbf{d f}$ & $\mathbf{p}$ \\
\hline BIM-IC Human Factor & & & & 0.431 & 85 & 0.663 \\
$\quad$ Parking Garages & 23 & 8.64 & 1.55 & & & \\
Commercial Buildings & 64 & 8.78 & 1.31 & & & \\
BIM-IC Technology Factor & & & & 0.771 & 85 & 0.443 \\
$\quad$ Parking Garages & 23 & 6.84 & 1.56 & & & \\
Commercial Buildings & 64 & 7.1 & 1.32 & & & \\
\hline
\end{tabular}

Given the three-factor structure of BIM-IB, research question 2 investigated the perceptions of the realized benefits of BIM implementation for all stakeholders by building type (e.g., parking garages versus commercial buildings). Results revealed no significant difference (Table 5) in the BIM-IB factor means based on building type. It should be noted that the mean scores $(\mathrm{M}=6.58-7.90)$ for the construction operations-, productivity- and design-related benefits indicate agreement that these benefits of BIM were realized on both parking garages and commercial buildings. From a practical perspective, this indicates that project stakeholders perceive no difference in the construction operations-, productivity- and design-related benefits realized on these projects regardless of whether the building being constructed was a commercial building or a parking garage. 
Table 5. Benefits of BIM Implementation: Construction Operations-, Productivity- and Design-Related Factors by Building Type (RQ2).

\begin{tabular}{ccccccc}
\hline Variable & $\mathbf{N}$ & $\mathbf{M}$ & $\mathbf{S D}$ & $\mathbf{t}$ & $\mathbf{d f}$ & $\mathbf{p}$ \\
\hline BIM-IB Construction Operations & & & & 0.426 & 85 & 0.671 \\
$\quad$ Parking Garages & 23 & 6.91 & 1.72 & & & \\
Commercial Buildings & 64 & 7.13 & 2.15 & & & \\
BIM-IB Productivity & & & & 0.781 & 85 & 0.437 \\
$\quad$ Parking Garages & 23 & 6.58 & 2.17 & & & \\
Commercial Buildings & 64 & 7.03 & 2.44 & & & \\
$\quad$ BIM-IB Design & & & & 0.251 & 85 & 0.802 \\
Parking Garages & 23 & 7.78 & 1.93 & & & \\
Commercial Buildings & 64 & 7.90 & 1.83 & & & \\
\hline
\end{tabular}

Given the observed two-factor structure of BIM-IC, research question 3 investigated project stakeholders' (e.g., Architects, Owners and General Contractors) perceptions of the impact of the human- and technology-related factors on successful BIM implementation. While the mean perceptions (Table 6) of the impact of the human factor on successful BIM implementation were all positive and strong $(\mathrm{M}=8.81-9.07)$, ANOVA (Table 7) revealed no significant difference in mean perceptions by stakeholder. However, a significant difference $(\mathrm{p}=0.014)$ was observed on mean perceptions of the impact of the technology factor on successful BIM implementation. Planned comparison post hoc analysis revealed the difference in mean perception was observed between Architects $(M=6.60, S D=$ 1.23) and Owners ( $\mathrm{M}=8.07, \mathrm{SD}=1.39)$, notably Owners perceived a higher level of positive impact for the technology factor than did Architects. It should be noted, and as further discussed below, that the sample of Owners was small $(n=9)$ which can impact the statistical power of this finding.

Table 6. Human and Technology Factor Descriptive Statistics by Stakeholder (RQ3).

\begin{tabular}{ccccc}
\hline Stakeholder & N & Mean & SD & $\mathbf{9 5 \% ~ C I ~}$ \\
\hline Human Factor & & & & \\
General Contractors & 47 & 8.81 & 1.40 & {$[8.39,9.21]$} \\
Architects & 31 & 8.85 & 1.39 & {$[8.04,8.57]$} \\
Owners & 9 & 9.07 & 1.42 & {$[8.16,9.99]$} \\
Technology Factor & & & & \\
General Contractors & 47 & 7.12 & 1.38 & {$[6.71,7.53]$} \\
Architects & 31 & 6.60 & 1.23 & {$[6.15,7.05]$} \\
Owners & 9 & 8.07 & 1.39 & {$[7.00,9.14]$} \\
\hline
\end{tabular}

Table 7. One-Way ANOVA Project Characteristics for Successful BIM: Human and Technology Factor by Stakeholder (RQ3).

\begin{tabular}{cccccc}
\hline Variable & df & SS & MS & F & p \\
\hline BIM-IC: Human Factor & & & & & \\
Between Groups & 2 & 2.3 & 1.149 & 0.606 & 0.548 \\
Within Groups & 84 & 159.19 & 1.895 & & \\
$\quad$ Total & 86 & 161.49 & & & \\
BIM-IC: Technology Factor & & & & & \\
Between Groups & 2 & 15.81 & 7.906 & 4.476 & 0.014 \\
Within Groups & 84 & 148.36 & 1.776 & & \\
$\quad$ Total & 86 & 164.18 & & & \\
\hline
\end{tabular}

Given the three-factor structure of BIM-IB, research question 4 investigated project stakeholders' (e.g., Architects, Owners and General Contractors) perceptions of the realized benefits of BIM implementation. ANOVA revealed no significant difference (Table 8) in stakeholder mean perceptions of the construction operations-, productivity- and design-related benefits of BIM implementation. 
However, is should be noted that stakeholder mean perceptions (Table 9) for the construction operations-, productivity- and design-related benefits were all positive.

Table 8. One-Way ANOVA: Construction Operations-, Productivity- and Design-Related Realized Benefits by Stakeholder (RQ4).

\begin{tabular}{cccccc}
\hline Variable & df & SS & MS & F & p \\
\hline Construction Operations Benefits & & & & & \\
Between Groups & 2 & 2.51 & 1.25 & 0.297 & 0.744 \\
Within Groups & 84 & 354.70 & 4.22 & & \\
$\quad$ Total & 86 & 357.21 & & & \\
Productivity Benefits & & & & & \\
Between Groups & 2 & 28.00 & 13.99 & 2.584 & 0.081 \\
Within Groups & 84 & 455.02 & 5.42 & & \\
$\quad$ Total & 86 & 483.01 & & & \\
Design Benefits & & & & & \\
Between Groups & 2 & 0.83 & 0.41 & 0.119 & \\
Within Groups & 84 & 291.94 & 3.48 & & \\
$\quad$ Total & 86 & 292.77 & & &
\end{tabular}

Table 9. Descriptive Statistics by Stakeholder: Construction Operations-, Productivity- and Design-Related Realized Benefits (RQ4).

\begin{tabular}{ccccc}
\hline Stakeholder & N & Mean & SD & 95\% CI \\
\hline Construction Operations Benefits & & & & \\
General Contractors & 47 & 7.09 & 1.90 & {$[6.53,7.65]$} \\
Architects & 31 & 7.17 & 1.50 & {$[6.53,7.64]$} \\
Owners & 9 & 6.58 & 1.93 & {$[5.10,8.07]$} \\
Productivity Benefits & & & & \\
General Contractors & 47 & 7.39 & 1.75 & {$[6.70,8.10]$} \\
Architects & 31 & 6.17 & 2.26 & {$[5.34,7.00]$} \\
$\quad$ Owners & 9 & 6.92 & 2.35 & {$[5.11,8.73]$} \\
Design Benefits & & & & \\
General Contractors & 47 & 7.79 & 1.86 & {$[7.25,8.34]$} \\
Architects & 31 & 7.17 & 2.01 & {$[7.16,8.64]$} \\
Owners & 9 & 8.11 & 1.18 & {$[7.25,9.02]$} \\
\hline
\end{tabular}

\section{Discussion}

Regarding the project characteristics impacting the success of BIM implementation (BIM-IC) EFA demonstrated that the following six BIM-IC items loaded together in a human-related category: improved team work and collaboration, BIM-integrated project meetings, early trade contractor involvement, project design development in BIM, enhanced communication among team members, and general contractor's (GC's) early involvement in design team model. These six items loaded in a logical order suggesting their interdependence in achieving successful BIM implementation. For example, BIM-integrated meetings could help improve team work and collaboration and enhance communication among team members while early GC and trade contractor involvement could improve project design development in BIM. Similarly, early GC and trade contractor involvement may improve team work and collaboration and enhance communication among team members, leading to successful BIM implementation. Additionally, improved team work and collaboration and enhanced communication among team members can lead to better project design development in BIM and, therefore, successful BIM implementation.

These findings correspond to the results of the previous research that also looked at the human-related characteristics that affect success of BIM implementation on a project. Similar to our study, Dodge Data \& Analytics [5] found that improved team work, BIM-integrated project meetings, 
early trade contractor involvement, GC early involvement in design team model, and project design development in BIM were the project characteristics that influence successful BIM implementation. Various authors [3-6,9,15,22,24,41] indicated that the success of BIM implementation depends on establishing collaboration among stakeholders as well as enhanced communication among team members.

EFA also indicated loading of the following five BIM-IC items in the technology-related category that influence the success of BIM implementation: BIM/modeling guidelines from client, standards to guide implementation, clear definition of technology-related deliverables, availability of trained professionals using BIM tools, and reduced software issues. For example, use of BIM guidelines provided by an owner and use of implementation standards could help to clearly define BIM-related deliverables leading to more successful BIM implementation. BIM success on a project is also positively impacted by reduced software issues such as improved interoperability as well as by presence of BIM-savvy professionals.

The findings herein confirm the results of the previous studies $[4,5,42]$ that indicate that the existence of BIM/modeling guidelines from the client and standards to guide BIM implementation have positive impacts on BIM implementation. Clear definition of technology-related deliverables was determined to have influence on success of BIM implementation by both the current study and the survey conducted by Dodge Data \& Analytics [5]. Finding that the availability of BIM-savvy professionals on a project is crucial for successful BIM implementation corresponds with the results of the previous research by Ozorhon and Karahan [4], Ghaffarainhoseini et al. [28], Dodge Data \& Analytics [5] Won and Lee [19], Son et al. [40], Barlish and Sullivan [7], Shang and Shen [42], Won et al. [15], Ratajczak et al. [36] and Koseoglu et al. [23]. Reduced software issues are also an important technology-related BIM-IC item that leads to successful BIM implementation according to the current study as well as studies by Liu et al. [24], Ozorhon and Karahan [4], Ghaffarainhoseini et al. [28], Lee et al. [25], Son et al. [40], Wang and Song [33], Ahn et al. [6], Shang and Shen [42], and Bryde et al. [9].

Regarding realized benefits of BIM implementation (BIM-IB) EFA of BIM-IB items indicated loading of the following three BIM-IB items in a construction operations category: improved process and accuracy of estimating construction costs, improved accuracy and completeness of bids, and improved ability to plan construction phasing and logistics. Factor loadings suggest that these three items are related; for example, use of BIM improves the estimating processes and the ability to plan construction phasing and logistics. Also, these benefits lead to improved accuracy and the completeness of bids. Results confirm those of the previous studies. For example, Dodge Data \& Analytics [5] survey also pointed out the BIM implementation was beneficial for construction operations; more specifically BIM helped to improve the estimating of construction costs, accuracy and completeness of bids, and ability to plan construction phasing and logistics.

In productivity-related category the following two BIM-IB items loaded together: increased predictability/fewer unplanned changes and reduced rework. This shows a logical relationship between the items because fewer unplanned changes lead to reduced rework and overall time and cost benefits for the owner. Our finding that BIM is causing fewer unplanned changes corresponds to the findings by Barlish and Sullivan [7], McGraw Hill Construction [2], and Ghaffarainhoseini et al. [28]. Similar to other studies $[2,30,33]$, our research also indicated that BIM use results in less rework.

In the design-related category EFA indicated loading of three BIM-IB items: increased understanding of proposed design solutions, increased ability to actively participate in the design process, and improved quality/function of final design. This finding is expected because active participation of the stakeholders in the design process leads to better understanding of the design and, consequently, improves quality of the final design. The results of the current study confirm those found by Dodge Data \& Analytics [5] (e.g., BIM use leading to improved understanding of proposed design solutions and increased ability to actively participate in the design process). In the case of improved quality of the final design due to use of BIM, our finding confirms the findings of previous studies such as Meittinen and Paavola [22], Xing and Tao [29], Bryde et al. [9], Ghaffarainhoseini et al. [28], Arayci 
et al. [35], Ahn et al. [6], Bryde et al. [9], McGraw Hill Construction [2], Won and Lee [19], and Dodge Data \& Analytics [5].

Regarding differences in perceptions of BIM-IC items that impact BIM implementation when compared by building type (RQ1), t-test showed that there were no significant differences between respondent perceptions about human- and technology-related BIM-IC items given the building type (i.e., project garages and commercial buildings). Further, the impact of human- and technology-related BIM-IC items on the success of BIM implementation was positive regardless of whether the project was a commercial building or a parking garage. This is an interesting finding because the literature review indicates that the complexity and project size affect success of BIM implementation $[4,10,15,23]$. The current study findings contradict the studies noted since no discernable difference in the perception of BIM-IC was observed between commercial building and parking garages for all stakeholder types

In regard to differences in perceptions of the realized benefits of BIM implementation (BIM-IB) when compared by building type (RQ2), t-test showed that there were no significant differences between respondent perceptions when compared by building type (i.e., parking garages and commercial buildings). This is an interesting finding as previous studies indicate that BIM benefits are typically experienced on complex projects such as commercial buildings. For example, Eastman et al. [12] found that BIM is particularly useful for visualizing project phasing on complex projects which differs from our finding. On the other hand, Ozorhon and Karahan [4] pointed out that, in Turkey, BIM will be more likely adopted on simple residential projects than on complex industrial projects.

ANOVA (RQ3) revealed no significant difference in mean perceptions of the BIM-IC human factor by project stakeholder type (Architects, General Contractors and Owners). The perceptions of the three stakeholder groups were all positive and strong. This is a useful but unexpected finding. The authors would, for example, expect that architects favor more project design development in BIM as compared to GCs and owners. However, Dodge Data \& Analytics [5] survey showed that owners more than architects and GCs valued project designs developed in BIM. Our findings also differ from those stated by Dodge Data \& Analytics [5] which suggest that GCs, more than owners and architects, indicated a larger impact of GC and trade contractor early involvement. In regard to improved communication among team members, our findings correspond to those revealed in the Dodge Data \& Analytics [5] survey where in about half of respondents in each stakeholder category found that communication was an important success factor. Finally, the majority of respondents in each stakeholder category reported that the improved teamwork and collaboration, as well as BIM-integrated project meetings, contributed to the success of the complex projects [5].

ANOVA (RQ3) revealed a significant difference in mean perceptions of the BIM-IC technology factor by project stakeholder type (Architects, General Contractors and Owners). Post hoc analysis revealed the significant difference was between Owners and Architects. This is an expected finding as owners may favor providing BIM guidelines to the AEC team as well as the standards for BIM guide implementation while architects might feel that the requirement to use BIM guides and standards might disrupt the BIM workflow, as well as restrict their freedom and creativity. On the other hand, owners might not be directly affected by software issues and the availability of BIM-trained professionals, and it should be noted that these two items can have an important effect on architect ability to deliver high-quality design.

ANOVA (RQ4) revealed no significant differences in mean perceptions of the BIM-IB construction operations-, productivity- or design-related factors by project stakeholder type (Architects, General Contractors and Owners). However, as noted above, the perceptions of each stakeholder group were all positive. Similar to our findings the majority of survey respondents in each stakeholder category agreed that BIM improved process and accuracy of both cost estimating and bidding as well as construction phasing and logistics, increased predictability and led to fewer unplanned changes [5]. 


\section{Conclusions}

The aim of the study was to investigate the perceptions of different project stakeholders (Architects, General Contractors and Owners) regarding project characteristics (BIM-IC) that impact the success of BIM implementation and the realized benefits of BIM implementation (BIM-IB) on simple versus complex projects. The study compared commercial buildings as an example of a complex project type with parking garages that were considered simple buildings. The online survey instrument was distributed to Architects, Engineers, Consultants, General Contractors, Subcontractors and Owners. Incomplete survey responses were culled as well as responses of the participants that indicated that they did not use BIM. Due to the small number of respondents in some groups, engineers, consultants and "other" stakeholders were also culled. Thus, only responses from Architects, General Contractors and Owners were analyzed.

Exploratory Factor Analysis (EFA), showed that the project stakeholders perceived that several human-related BIM-IC items (such as improved team work and collaboration, BIM-integrated project meetings, early trade contractor involvement, project design development in BIM, enhanced communication among team members, and GC early involvement in the model) contributed to successful BIM implementation. Similarly, BIM/modeling guidelines from client, standards to guide implementation, clear definition of technology-related deliverables, availability of trained professionals using BIM tools, and reduced software issues were the technology-related BIM-IC items that the stakeholders perceived to impact the success of BIM implementation.

The stakeholders perceived that BIM implementation on projects resulted in a construction operation benefits factor (e.g., improved process and accuracy of estimating construction costs, improved accuracy and completeness of bids, and improved ability to plan construction phasing and logistics), a productivity-related benefits factor (e.g., increased predictability/fewer unplanned changes and reduced rework) and a design-related benefits factor (e.g., increased understanding of proposed design solutions, increased ability to actively participate in the design process, and improved quality/function of the final design).

An important finding of the study was that no significant differences in General Contractor and Architects' perceptions of the impact of the human- and technology-related BIM-IC factors on successful BIM implementation were observed when compared by building type (i.e., project garages and commercial buildings). This finding is in contrast to the previous research that indicate a larger impact of BIM-IC items on BIM implementation in the case of complex projects. Similarly, it is noteworthy that stakeholders did not report significantly different opinions regarding the realized benefits of BIM implementation on project garage and commercial building projects. This finding is important because previous studies emphasized that BIM was more beneficial on complex projects than simple projects. This result could be interpreted to show that, since the perception of BIM-IB did not differ based on project type, that BIM implementation is becoming/has become a standard method of project development and delivery that is utilized on all project types, not just large and complex structures.

The perceptions of Architects, General Contractors and Owners did not significantly differ when considering the impacts of the human-related factor on the success of BIM implementation. However, Owners and Architects reported significantly different opinions about the impact of the technology-related BIM-IC factor on BIM success. Interestingly, these three stakeholders agreed about the realized benefits of BIM implementation while reporting different perceptions of what leads to the successful implementation of BIM.

This study contributes to the body of knowledge by identifying and empirically grouping project characteristics that impact the success of BIM implementation as well as the realized benefits of BIM. Additionally, the results shed light on the similarities and differences in stakeholder perceptions of BIM-IB and BIM-IC on simple versus more complex projects. This is important because previous studies have generally focused on complex projects. The study provides an important finding that the project stakeholders (Architect, General Contractor and Owner) surveyed did not see significant 
differences between the human-related project characteristics that impact BIM implementation when it comes to parking garage and commercial building projects. Similarly, the study revealed an important finding that the three different stakeholder groups agreed with the realized benefits of BIM use on both parking garage and commercial building projects. This study represents an important empirical step by demonstrating that decisions to implement BIM may not be based on project complexity, but rather that the benefits of BIM implementation are being realized on simpler projects as well as complex projects.

While further research is needed, the findings herein provide initial evidence that BIM is, or has become, a standard for design and project delivery process, and perhaps a project's characteristics and the potential to realize benefits are less important pieces in the stakeholder's decision to implement BIM on a given project. Another important area of future inquiry includes an investigation of the impact of the ever-increasing availability of inexpensive and user friendly BIM technologies on increased BIM implementation as a standard practice in construction project design and delivery. As BIM technologies become cheaper and more user-friendly, it is realistic that the proverbial break-even point on the adoption of BIM becomes less formidable which will contribute to more widespread use of the technology. Finally, research regarding whether the "decision" to implement BIM is in fact a "decision" at all might be prudent. That is, researchers should investigate if BIM is (or is moving toward) a standard operating procedure for AEC stakeholders when designing and delivering projects, and the technology is implemented regardless of the project type or perceived benefits of implementation.

\section{Limitations and Interpretation of the Findings}

Several limitations, including, but perhaps not limited to, the following, should be considered when interpreting the results. It should be noted that this study was conducted under the assumption that parking structures are "simple" projects. While this generalization was necessary to group the buildings by type, it should be considered when interpreting the results. Secondly, a small number of owners $(12 \%)$ participated in the survey. Sub-aggregation of the sample produced small sample sizes in the analysis by stakeholder (research questions RQ3 and RQ4). The survey was sent to potential respondents by one general contractor and one land grant university in the state of Colorado; therefore, findings may not be generalizable to other samples and extrapolation of the findings herein should be completed with caution. Future research should include larger sample size particularly aiming to reach more owners. It should be noted that this study was conducted under the premise that the project characteristics impacting successful BIM implementation and realized benefits thereof was an exhaustive and comprehensive list. While these were obtained directly from the Dodge Data \& Analytics [5] survey, interpretations of the results should be made in consideration of the assumptions and delimitations of the original survey. Sub-aggregation of the data by variables such as project cost, project schedule, number of RFIs, time to respond to RFIs, and project delays was not prudent due to reductions in sample size. Thus, a follow-up study, with a larger overall sample, should focus on the investigation of the impact of these project characteristics on BIM-IC and BIM-IB. The above noted limitations present opportunities to continue this line of research in the future among larger and more diverse samples of project stakeholders.

Author Contributions: This research is a collaborative effort of two authors. Conceptualization, S.O. and J.W.E.; methodology, J.W.E. and S.O.; formal analysis, J.W.E. and S.O.; investigation, J.W.E. and S.O.; writing-original draft preparation, S.O. and J.W.E.; writing-review and editing, S.O. and J.W.E.

Funding: This research received no external funding.

Conflicts of Interest: The authors declare no conflict of interest.

\section{References}

1. National Institute of Building Sciences (NIBS) building SMART alliance. National BIM Standard-United States, Version 3; National Institute of Building Sciences: Washington, DC, USA, 2015. 
2. McGraw Hill Construction. The Business Value of BIM in North America: Smart Market Report; McGraw Hill Construction Research \& Analytics: Bedford, MA, USA, 2012.

3. Antwi-Afari, M.F.; Li, H.; Pärn, E.A.; Edwards, D.J. Critical success factors for implementing building information modelling (BIM): A longitudinal review. Autom. Constr. 2018, 91, 100-110. [CrossRef]

4. Ozorhon, B.; Karahan, U. Critical success factors of Building Information Modeling implementation. J. Manag. Eng. 2017, 33, 1-10. [CrossRef]

5. Dodge Data \& Analytics. Measuring the Impact of BIM on Complex Buildings: Smart Market Report; Dodge Data \& Analytics: Bedford, MA, USA, 2015.

6. Ahn, Y.; Kwak, H.; Suk, J. Contractors' transformation strategies for adopting building information modeling. J. Manag. Eng. 2016, 32, 1-13. [CrossRef]

7. Barlish, K.; Sullivan, K. How to measure the benefits of BIM-A case study approach. Autom. Constr. 2012, 24, 149-159. [CrossRef]

8. Becerik, B.; Pollalis, S. Computer Aided Collaboration in Managing Construction; Harvard University Graduate School of Design: Cambridge, MA, USA, 2006.

9. Bryde, D.; Broquetas, M.; Volm, M.J. The project benefits of Building Information Modelling (BIM). Int. J. Proj. Manag. 2013, 31, 971-980. [CrossRef]

10. Cao, D.; Wang, G.; Li, H.; Skitmore, M.; Huang, T.; Zhang, W. Practices and effectiveness of building information modelling in construction projects in China. Autom. Constr. 2015, 49, 113-122. [CrossRef]

11. Chen, K.; Lu, W.; Peng, Y.; Rowlinson, S.; Huang, G.Q. BIM bridging and building: From a literature review to an integrated conceptual framework. Int. J. Proj. Manag. 2015, 33, 1405-1416. [CrossRef]

12. Eastman, C.; Teicholz, P.; Sacks, R.; Liston, K. BIM Handbook: A Guide to Building Information Modeling for Owners, Managers, Designers, Engineers, and Contractors, 2nd ed.; John Wiley and Sons: Hoboken, NJ, USA, 2011.

13. Giel, B.K.; Issa, R.R. Return on investment analysis of using building information modeling in construction. J. Comput. Civ. Eng. 2013, 27, 511-521. [CrossRef]

14. Lu, N.; Korman, T. Implementation of Building Information Modeling (BIM) in Modular Construction: Benefits and challenges. In Proceedings of the Construction Research Congress, Banff, AB, Canada, 8-10 May 2010; pp. 1-10.

15. Won, J.; Lee, G.; Dossick, C.; Messner, J. Where to focus for successful adoption of building information modeling within organization. J. Constr. Eng. Manag. 2013, 139, 04013014. [CrossRef]

16. Cavka, H.C.; Staub-French, S.; Pottinger, R. Evaluating the alignment of organizational and project contexts for BIM adoption: A case study of a large owner organization. Buildings 2015, 5, 1265-1300. [CrossRef]

17. Dasovic, B.; Galic, M.; Klanšek, U. Active BIM approach to optimize work facilities and tower crane locations on construction sites with repetitive operations. Buildings 2019, 9, 21. [CrossRef]

18. Shan, Y.; Goodrum, P.M. Integration of building information modeling and critical path method schedules to simulate the impact of temperature and humidity at the project level. Buildings 2014, 4, 295-319. [CrossRef]

19. Won, J.; Lee, G. How to tell if a BIM project is successful: A goal-driven approach. Autom. Constr. 2016, 69, 34-43. [CrossRef]

20. Carson, J. Can BIM successfully deliver small construction projects? The National Building Specification (NBS); Royal Institute of British Architects (RIBA) Enterprises Ltd.: London, UK, 2018.

21. The National Building Specification (NBS). National BIM Report 2019: The Definitive Industry Update; Royal Institute of British Architects (RIBA) Enterprises Ltd.: London, UK, 2019.

22. Miettinen, R.; Paavola, S. Beyond the BIM utopia: Approaches to the development and implementation of building information modeling. Autom. Constr. 2014, 43, 84-91. [CrossRef]

23. Koseoglu, O.; Keskin, B.; Ozorhon, B. Challenges and enablers in BIM-enabled digital transformation in mega projects: The Istanbul new airport project case study. Buildings 2019, 9, 115. [CrossRef]

24. Liu, Y.; van Nederveen, S.; Hertogh, M. Understanding effects of BIM on collaborative design and construction: An empirical study in China. Int. J. Proj. Manag. 2017, 35, 686-698. [CrossRef]

25. Lee, S.; Yu, J.; Jeong, D. BIM Acceptance Model in Construction Organizations. J. Manag. Eng. 2015, $31,1-13$. [CrossRef]

26. Nawari, N.O. BIM standard in off-site construction. J. Archit. Eng. 2012, 18, 107-113. [CrossRef]

27. Krygiel, E.; Nies, B. Green BIM: Successful Sustainable Design with Building Information Modeling; Wiley: Indianapolis, IN, USA, 2008. 
28. Ghaffarianhoseini, A.; Tookey, J.; Ghaffarianhoseini, A.; Naismith, N.; Azhar, S.; Efimova, O.; Raahemifar, K. Building Information Modelling (BIM) uptake: Clear benefits, understanding its implementation, risks and challenges. Renew. Sustain. Energy Rev. 2017, 75, 1046-1053. [CrossRef]

29. Xing, D.; Tao, J. Design and Application of Green Building based on BIM. In Proceedings of the Geo-Informatics in Resource Management and Sustainable Ecosystem: Third International Conference (GRMSE 2015), Wuhan, China, 16-18 October 2015; pp. 901-907.

30. Zheng, L.; Lu, W.; Chen, K.; Chau, K.W.; Niu, Y. Benefit sharing for BIM implementation: Tackling the moral hazard dilemma in inter-firm cooperation. Int. J. Proj. Manag. 2017, 35, 393-405. [CrossRef]

31. Uusitalo, P.; Seppänen, O.; Lappalainen, E.; Peltokorpi, A.; Olivieri, H. Applying level of detail in a BIM-based project: An overall process for lean design management. Buildings 2019, 9, 109. [CrossRef]

32. Taylor, J.E.; Bernstein, P.G. Paradigm trajectories of building information modeling practice in project networks. J. Manag. Eng. 2009, 25, 69-76. [CrossRef]

33. Wang, G.; Song, J. The relation of perceived benefits and organizational supports to user satisfaction with building information model (BIM). Comput. Hum. Behav. 2017, 68, 493-500. [CrossRef]

34. Zuppa, D.R.; Issa, R.A.; Suermann, P.C. BIM's Impact on the Success Measures of Construction Projects. In Proceedings of the International Workshop on Computing in Civil Engineering, Austin, TX, USA, 24-27 June 2009; pp. 503-512.

35. Arayici, Y.; Coates, P.; Koskela, L.; Kagioglou, M.; Usher, C.; O’Reilly, K. Technology adoption in the BIM implementation for lean architectural practice. Autom. Constr. 2011, 20, 189-195. [CrossRef]

36. Ratajczak, J.; Riedl, M.; Matt, D.T. BIM-based and AR Application combined with location-based management system for the improvement of the construction performance. Buildings 2019, 9, 118. [CrossRef]

37. Zou, Y.; Kiviniemi, A.; Jones, S.W. A review of risk management through BIM and BIM-related technologies. Saf. Sci. 2017, 97, 88-98. [CrossRef]

38. Fargnoli, M.; Lleshaj, A.; Lombardi, M.; Sciarretta, N.; Di Gravio, G. A BIM-based PSS approach for the management of maintenance operations of building equipment. Buildings 2019, 9, 139. [CrossRef]

39. Verghote, A.; Al-Haddad, S.; Goodrum, P.; Van Emelen, S. The effects of information format and spatial cognition on individual wayfinding performance. Buildings 2019, 9, 29. [CrossRef]

40. Son, H.; Lee, S.; Kim, C. What drives the adoption of building information modeling in design organizations? An empirical investigation of the antecedents affecting architects' behavioral intentions. Autom. Constr. 2015, 49, 92-99. [CrossRef]

41. Hamdi, O.; Leite, F. Conflicting side of Building Information Modeling implementation in the construction industry. J. Leg. Aff. Disput. Resolut. Eng. Constr. 2014, 6, 1-8. [CrossRef]

42. Shang, Z.; Shen, Z. Critical Success Factors (CSFs) of BIM Implementation for Collaboration Based on System Analysis. In Proceedings of the 2014 International Conference on Computing in Civil and Building Engineering, Orlando, FA, USA, 23-25 June 2014; pp. 1441-1448.

43. Pett, M.A.; Lackey, N.R.; Sullivan, J.J. Making Sense of Factor Analysis: The Use of Factor Analysis for Instrument Development in Health Care Research; Sage: Thousand Oaks, CA, USA, 2003.

44. Lozano, L.M.; Garcia-Cueto, E.; Muniz, J. Effect of the number of response categories on the reliability and validity of rating scales. Methodol. Eur. J. Res. Methods Behav. Soc. Sci. 2008, 4, 73-79. [CrossRef]

45. Chimi, C.J.; Russell, D.L. The Likert Scale: A proposal for improvement using Quasi-continuous variables. In Proceedings of the Information Systems Education Conference, Washington, DC, USA, 8 November 2009; pp. 1-10.

46. Johns, R. One size doesn't fit all: Selecting response scales for attitude items. J. Elect. Public Opin. Parties 2005, 15, 237-264. [CrossRef]

47. Krosnick, J.A.; Holbrook, A.L.; Berent, M.K.; Carson, R.T.; Hanemann, W.; Kopp, R.J.; Mitchell, R.C.; Presser, S.; Ruud, P.A.; Smith, V.K.; et al. The impact of 'no opinion' response options on data quality: Non-attitude reduction or an invitation to satisfice? Public Opin. Q. 2002, 66, 371-403. [CrossRef]

48. Field, A. Discovering Statistic Using SPSS, 3rd ed.; Sage: London, UK, 2009.

(C) 2019 by the authors. Licensee MDPI, Basel, Switzerland. This article is an open access article distributed under the terms and conditions of the Creative Commons Attribution (CC BY) license (http://creativecommons.org/licenses/by/4.0/). 